
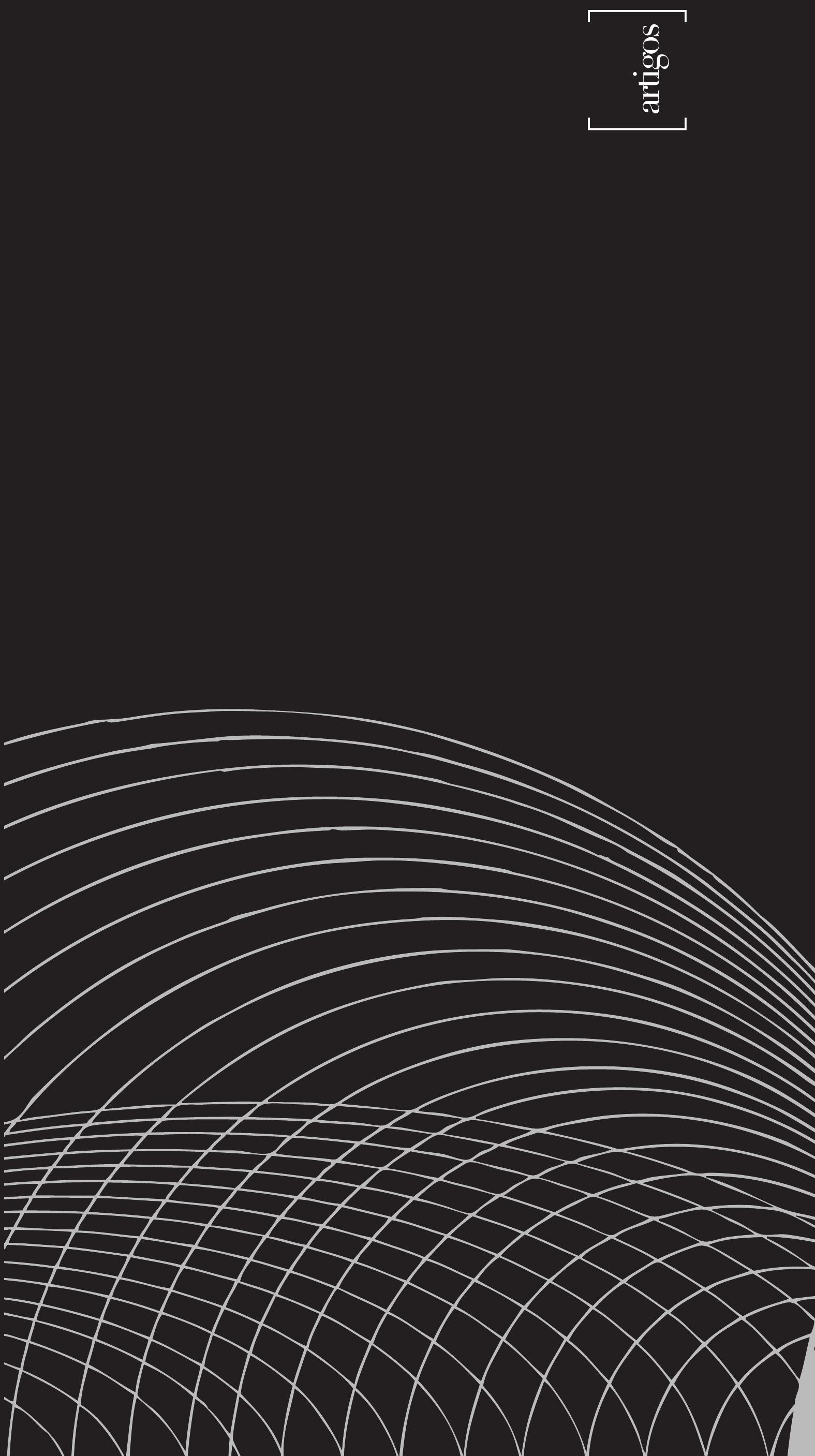


\section{arisge \\ Potencialidade do ritmo em processos de significação de textos visuais}

\section{The potential of rhythm \\ to convey meaning in visual texts}

[ SANDRA RAMALHO E OLIVEIRA ]

Doutora em Comunicação e Semiótica pela PUC-SP com pós-doutorado em Paris, sob a direção de Andrea Semprini. Professora e pesquisadora. Atua na Graduação e Mestrado em Artes Visuais da Universidade do Estado de Santa Catarina - UDESC. É a atual presidente da ANPAP e autora dos livros Imagem também se lê e Moda também é texto (São Paulo: Rosari, 2005 e 2007).

E-mail: ramalho@floripa.com.br

[resumo] 0 fenômeno conhecido como ritmo está presente nos mais diferentes processos, desde a gestação da vida, passando pelos batimentos cardiacos, pela organização do dia em horas, pelas estações do ano, pelos processos de comunicação e por todo o campo da visualidade. Se o ritmo sonoro é perceptivel à audição, o ritmo visual, conseqüentemente, é perceptivel à visão.Trata-se de um aspecto inerente à maioria das imagens, como as do vestuário. Quando criamos imagens, muitas vezes concebemos ritmos. Destacar o ritmo visual tem o propósito de chamar a atenção para sua potencialidade no plano da expressão e no da significação. A bibliografia escassa sobre o tema é um sinalizador de uma lacuna teórica.

\section{palavras-chave}

ritmo visual; semiótica visual; leitura de imagens.

[abstract] The phenomenon known as rhythm is present in the most diverse processes, ranging from gestation of a new life, the beating of the heart, the subdivision of days into hours and the year into seasons, through communicative processes to the entire field of visual expression and interpretation. If the rhythm of sleep can be perceived via the sense of hearing, the visual rhythm is perceived through sight. It is an inherent characteristic of images. When we create an image, we also create rhythms. Exposing this rhythm implies calling attention to its potentials, both in the dimension of expression and the dimension of meaning. The scarcity of literature on the subject represents a theoretical gap that should be filled.

[key words] visual rhythm; visual semiotics; image analysis. 


\section{Do particular ao geral}

Vou fazer um recorte. Não de um tecido ou de um texto verbal. Mas um recorte de um dos aspectos das imagens: um fenômeno da criação e da percepção visual, portanto. Como este fenômeno não acontece isoladamente, ou seja, está em geral presente associado a outros fenômenos estético-visuais, ele pode passar despercebido. Sendo difícil isolá-lo, talvez o mais adequado não fosse falar em recorte, mas em puxar um fio da tessitura da trama que é o texto visual. Pretendo, ao expô-lo, propor novos modos para aproveitá-lo e, ao evidenciá-lo, chamar a atenção para suas múltiplas possibilidades. E mais que isso, refletir sobre o fato de, intencionalmente ou não, acabarmos gerando este fenômeno que pode ser identificado até mesmo no aspecto visual destas palavras (e na escrita de qualquer texto verbal).

Quando falamos em ritmo, logo nos vem à mente a noção de ritmo sonoro, especialmente o musical. $\mathrm{Ou}$ de ritmo na poesia. Entretanto, o fenômeno conhecido como ritmo se dá nos mais diferentes processos naturais: na gestação da vida e nos batimentos cardíacos, no movimento das ondas do mar, na organização do tempo e assim por diante. Quanto aos processos comunicacionais, desde os naturais até aqueles que envolvem a mais recente tecnologia, o ritmo também está presente.

Goethe chegou a afirmar que tudo na vida é ritmo. Este é, portanto, antes de tudo, um fenômeno vital. Encontramos ritmo nos movimentos de rotação e translação da Terra, o que explica a divisão do tempo em dias, anos e estações do ano. Existe ritmo na chuva, nas marés, nas migrações dos animais, nas fases da lua, nos ciclos da flora, na vida dos animais e dos seres humanos, desde o cortejo, o sexo, a concepção, a gestação, o crescimento, enfim, em todo o ciclo da vida. Há ainda o ritmo do relógio biológico, do caminhar, da respiração, da pulsação, da digestão. Isto aponta para a importância do ritmo em si como um fenômeno não somente humano e cotidiano, mas também pluridimensional e planetário. Temos muito a perceber no que se refere a ritmo, muito mais do que se produziu e produz em termos de ritmos musicais, como pode ser observado.

\section{Do geral ao particular}

No campo da visualidade, temos então o ritmo visual. Interrompo a escritura deste artigo atraída pelo som de Sonho de amor, de Lizt, executado ao piano em um programa de TV. Diante da imagem na tela, além do ritmo da músi$\mathrm{ca}$, começo a observar o ritmo visual nas cordas do piano, nas teclas, nas dobras das mangas balonês da pianista, nas suas próprias mãos; não o ritmo dos movimentos que faz para tocar nas teclas, mas o ritmo visual determinado pelos seus dedos e pelos espaços, maiores ou menores, entre eles, a cada acorde. Havia muito mais ritmos na audição musical do que na música propriamente dita.

Mas é como um processo gerador de efeitos de sentido que interessa aqui abordar o ritmo visual. Meu foco está nos aspectos físicos, perceptíveis ao olhar, do ritmo nas imagens visuais, denominado plano de expressão e, ao mesmo tempo, com os sentidos que eles geram, dimensão da imagem denominada plano de conteúdo pela semiótica discursiva. Isto porque o campo da semiótica tem como foco não só o que diz a imagem, mas o modo por meio do qual ela diz o que diz. E o modo como ela diz encontra-se registrado no plano de expressão, naquilo que pode ser percebido pelos cinco sentidos, o que, no caso da visualidade, se refere especialmente à visão. Portanto, considerando-se o texto visual, seja uma obra de arte, seja um objeto utilitário, interessa o ritmo visual como uma das articulações entre elementos, grosso modo, uma das "sintaxes" simultâneas do texto visual.

Eis aí o recorte, ou o fio puxado da intrincada trama que é o texto visual: 0 potencial de significados das articulações de sentido provenientes das relações entre os diversos elementos constitutivos que compõem uma imagem visual, presencial ou impressa em qualquer mídia.

Por outro lado, o ritmo visual consiste, igualmente, em um fenômeno estético, se considerarmos a palavra estética no seu sentido etimológico, qual seja, perceber, sentir, ou percepção por meio dos nossos sentidos. Se o ritmo sonoro é perceptível ao sentido da audição, o ritmo visual, conseqüentemente, é perceptível à visão. Perceber ritmos é, em sínte$s e$, perceber diferenças entre elementos 
similares, no tempo e/ou no espaço.

Ajustando nosso foco nessa questão específica dos textos visuais, é possível identificar e classificar ritmos regulares e irregulares em praticamente qualquer produto visual. Isto se aplica ao plano de expressão das imagens, sejam elas artísticas ou pertencentes ao universo estético cotidiano, como, por exemplo, os produtos do vestuário.

0 ritmo visual está em uma seqüência de botões, em pespontos, em estampas, em dobras, pregas, cortes, costuras, de um modo mais evidente. Está também nas texturas, de uma maneira mais tênue. Assim, o elemento constitutivo do ritmo visual pode ser tanto uma cor, uma forma, uma linha, como um botão, que, na verdade, é composto pela associação de uma forma a uma cor. Interessante é observar a diversidade de combinações de elementos e a conseqüente multiplicidade de efeitos visuais do que em um conjunto de colares de contas. Entretanto, os colares são lineares; assim, diante de uma quantidade deles, pode-se observar a diversidade, mas não a complexidade que o ritmo visual pode gerar, como ocorre em uma estampa de um tecido, por exemplo.

Importante ainda lembrar que o ritmo visual está presente na produção das mais distintas sociedades, independentemente de suas origens, natureza ou época: encontramos o ritmo visual em sociedades primitivas, assim consideradas em termos cronológicos, ou primitivas, em termos de nível de elaboração dos produtos, embora vivam no presente. Em ambas é comum encontrar faixas decorativas na cerâmica utilitária, cuja concepção é regida pela regra do ritmo regular (elemento $x_{i}$ elemento $y_{i}$ elemento $x_{i}$ elemento $y$ e assim sucessivamente). $E$ encontramos igualmente o ritmo visual nas sociedades contemporâneas pós-industriais e tecnológicas, apresentado dos mais diversos modos.

\section{0 mesmo ritmo,}

\section{outras abordagens}

A bibliografia escassa sobre o tema é um forte sinalizador de uma lacuna teórica. A noção de ritmo visual, diluída em esparsos textos sobre diferentes linguagens, parece se aplicar a manifestações culturais recorrentes em qualquer sociedade, da cerâmica ao cinema, do vestuário ao design, o que autorizaria uma exploração mais detida e específica em relação à sua efetiva participação na espécie de sintaxe dessas diferentes linguagens visuais.

Um dos autores que aborda o assunto é Jacques Aumont. Reportando-se a Klee, Aumont rememora suas reflexões expressas na obra Esquisses pédagogiques, de 1925. Com base em Klee, ele trata da questão do ritmo visual, que define como a "oposição entre estrutura dividual e estrutura individual" (1992, p. 268), ou seja, o ritmo visual é o resultado do contraste entre um elemento ou um bloco de elementos indivisíveis na obra e elementos que se dividem em várias partes idênticas.

Analisando essa idéia, é possivel verificar que certos elementos - uma cor, uma forma, uma determinada linha - podem estar presentes em um texto, de maneira fragmentada; são o que Aumont chama de estruturas dividuais (AUMONT, 1992). Analisados cada um desses elementos no seu conjunto e em oposição aos intervalos entre eles, observa-se o ritmo visual. Os intervalos - o fundo de uma composição visual, por exemplo - podem ser considerados então estrutura individual, mesmo sendo um todo ou um conjunto de elementos diferenciados que, em oposição àquele analisado, funciona como um todo contínuo.

Fazendo uma analogia com o ritmo sonoro, poderíamos dizer que a estrutura dividual é um conjunto de sons intermitentes e sucessivos e que a individual seria o conjunto formado pelo(s) silêncio(s) entre cada um deles.

Outro estudo que aborda o ritmo visual é de autoria de Pignatari (1989), no qual ele estabelece relações entre o ritmo poético e o ritmo visual determinado por portas e janelas, no desenho de fachadas arquitetônicas. Utilizando a terminologia proposta por Aumont, as paredes seriam a estrutura individual e as portas e janelas seriam a estrutura dividual, se vistas em oposição às paredes.

0 ritmo é analisado por Aumont (1992) na sua dimensão de movimento, no cinema e no vídeo. Ele estabelece diferença entre este tipo de ritmo e 0 ritmo na imagem fixa, afirmando que 0 ritmo temporal, da imagem audiovisual, não é o mesmo ritmo espacial do qual fala Klee em seu livro. Segundo ele, o ritmo no cinema é metafórico. Isto se deve ao fato de as imagens cinematográficas, 
televisuais e mesmo as infoimagens pressuporem a ilusão do movimento. É essa ilusão, determinada pelos cortes nas seqüências, que é considerada por Aumont como metáfora de ritmo.

Wong (1990) trata do fenômeno do ritmo visual como repetição; esta é a sua maneira de abordar composições visuais em que se destaca a variedade de ritmos, a maioria deles, regulares. 0 autor faz apenas uma breve menção ao ritmo: "toda a forma repetitiva é como uma batuta de um ritmo musical" (WONG, p. 18). Breve observação é também o que traz Souza, conceituando o ritmo como "uma recorrência de variações, as mais das vezes sob a forma de destaques e intervalos, com bastante similaridade para estabelecer continuidade e um plano de ordenamento" (1977, p. 35); ou, simplesmente, destaque e intervalos de elementos similares.

Ostrower (1986) fala do ritmo no contexto da tensão na composição visual. Deste modo, o fenômeno específico do ritmo fica diluido entre os demais aspectos que são geradores de tensão, bem como pelas questões históricas e pessoais nas quais situa obras e autores que usa como exemplo.

Por sua vez, Gomes Filho trata do ritmo no contexto do contraste, exemplificando e conceituando assim o ritmo visual: "movimento que pode ser caracterizado como um conjunto de sensações de movimentos encadeados ou de conexões visuais ininterruptas, na maior parte das vezes, uniformemente contínuas ou seqüenciais ou semelhantes ou, ainda, alternadas" (2000, p. 69).

Este é o resultado provisório de uma busca em autores que discutem as questões relacionadas à composição visual. É certo que se trata de um recorte de autores, aqui sim, um recorte, mas o pequeno espaço destinado ao ritmo visual em cada um deles já consiste em uma amostragem para confirmar a carência teórica.

\section{Tentando sintetizar}

0 que pode ser observado é que 0 ritmo visual é determinado pela ocorrência de um elemento constitutivo duas ou mais vezes em um mesmo texto, sempre intercalado por outro elemento. Esses elementos constitutivos visuais podem ser tanto pontos quanto linhas, formas, cores ou texturas que se repetem; ou dois desses elementos associados, como linhas de uma determinada cor, formas com determinada textura. Eles então formam seqüências, regulares ou não, lineares ou não.

Outro aspecto a ser destacado acerca do fenômeno denominado ritmo visual é o que me referi acima quando afirmei que os elementos que geram o ritmo visual são "intercalados" por outros elementos, ou seja, ao notar a recorrência de um elemento, percebemos uma determinada configuração, uma determinada forma, cor, textura, que se repete e que, além disso, estabelece com o seu entorno uma relação de contraste ou, no mínimo, de diferença. Daí, torna-se possível deduzir que para haver ritmo visual é necessário, além de uma seqüência de elementos repetidos, um fundo, ou uma relação distinta de elementos os quais podem, inclusive, gerar uma outra seqüência rítmica.

Um terceiro aspecto diz respeito à diversidade de ritmos visuais que podem ser criados ou observados em textos visuais. Eles podem se dar linearmente, na horizontal ou na vertical; ou em diagonais. É comum linhas rítmicas que se cruzam em uma mesma imagem ou em uma estampa. 0 ritmo visual pode ser irregular ou regular. Se for regular, pode se dar desde a simples justaposição $X Y X Y X Y X Y X$ até infinitas variações como $X Y-X Y-X Y-X Y$ ou $X X X Y X X X Y X X X Y X X X$ ou ainda $X \_X \_X$, todos exemplos muito singelos, posto que submetidos à linearidade do editor de texto. Podemos então considerar o ritmo regular como fruto da repetição ou alternância de elementos constitutivos ou microelementos em intervalos simétricos; e o irregular, quando os elementos constitutivos ou microelementos são distribuídos pelo texto visual sem respeitar qualquer padrão de medida entre eles.

Em sintese, é possivel afirmar que o ritmo visual se constrói a partir da sucessão (linear ou não) de presenças e ausências; ou que para haver ritmo é necessário haver repetição de elementos, contraste deles com outro(s) elemento(s) e que são infinitas as possibilidades em termos de composição de ritmos no texto visual.

\section{0 que diz o ritmo visual?}

Não se pode afirmar que os ritmos das linguagens estéticas, como os sistemas sonoro, cênico e visual, tenham sido criados como presentificação dos ritmos vitais e cósmicos, mas esta seria uma possibilidade a ser investigada. Entretanto, a semiótica discursiva não se ocupa da origem dos fenômenos de comunicação, mas de como se engendra 
a significação nas estruturas das manifestações, sejam elas textos verbais, visuais ou pertencentes a outros sistemas. Constatada a presença do ritmo visual na produção visual de praticamente toda sociedade, considero muito relevante investigar como ele gera efeitos de sentido, já que as imagens visuais são expostas a todos os cidadãos e estão permanentemente fazendo circular significações. Como o ritmo visual significa? Como os elementos e figuras que constituem o ritmo no texto visual se articulam no plano de expressão para propor significados e sentidos no plano do conteúdo?

De um modo geral, podemos considerar que o ritmo regular empresta, no caso de uma superfície lisa, características como ordem, clareza ou distinção, e também remete à garantia de qualidade, pois, em um tecido, por exemplo, com estampas compostas por ritmo regular, eventuais falhas seriam mais perceptiveis. Entretanto, no sentido inverso, o ritmo regular pode expressar o sentido de monotonia. Então, devem entrar em jogo outros elementos, como as cores e as formas, para neutralizar a monotonia da organização espacial. Ao contrário, um único elemento que se repete em todas as direções, como que disposto em linhas invisíveis, dispostas em todas as direções, em um tecido de bolinhas, por exemplo, pode suscitar os efeitos de alegria e movimento, mesmo que em cores discretas, como branco sobre preto ou marrom.

Voltemos aos botões: uma seqüência de botões, dada a repetição de um mesmo elemento, geralmente com for- ma circular, gera um determinado ritmo. E se os botões estão organizados de dois em dois, ou de três em três, o ritmo será diferente da organização mais usual. Isto pode encerrar um sentido lúdico, é claro, dependendo dos outros elementos do traje que com ele se relacionam.

Por seu turno, o ritmo irregular de pontos, linhas, formas, cores, texturas (ou de linhas que formam texturas), sem obedecer a regras estritas, especialmente a da medida constante de afastamento entre eles, pode oferecer efeitos de movimento, de originalidade, de inesperado, de criatividade.

Se não são meras suposições, não deixam de ser generalizações, estas quase tão imprecisas quanto as primeiras. Isto quer dizer que para um exercício justo da significação do ritmo em textos visuais é necessário um estudo particular de cada um desses textos, porque é praticamente impossível o ritmo ser a única "sintaxe" de um texto visual. Ao contrário da linguagem verbal, na linguagem visual cada elemento pode articular-se em múltiplas e concomitantes "sintaxes", de diferentes ordens. Assim, para estudos dos efeitos de sentido, necessário se faz observar também as demais relações entre os elementos estéticos constitutivos para uma devida apreensão de sua significação.

Contudo, é inegável o potencial de sentidos que o ritmo oferece às linguagens visuais, e sua onipresença através do tempo e do espaço é motivo suficiente para que nos atenhamos ao fenômeno. Portanto, é importante estarmos atentos a ele, ao criar e ao avaliar textos visuais. Até porque nada em um texto da arte, do design, da publicidade ou da moda é imune à produção de sentidos. Em outras palavras, tudo significa, a despeito da intencionalidade do seu autor.

\section{REFERÊNCIAS}

AUMONT, J. A Imagem. Campinas, Papirus, 1992.

GOMES Fo., J. Gestalt do objeto - sistema de leitura visual da forma. São Paulo, Escrituras, 2000.

KLEE. P. "Esquisses Pédagogiques". In: Théorie de l'art moderne. Paris, Éditions Denoël, 1985.

OSTROWER, F. Universos da arte. Rio de Janeiro, Campos, 1986.

PIGNATARI, D. 0 que é comunicação poética. São Paulo, Brasiliense, 1989.

SOUZA, A. Artes plásticas na escola. Rio de Janeiro, Bloch, 1977

WONG. W. Design bibimensionale. Milano, Ikon, 1990. 